\title{
Exogenous Cell Stimulation for Imaging Infection
}

\author{
S. Gratz ${ }^{*}, 1$, M. Gotthardt ${ }^{1,2}$, A. Pfestroff ${ }^{1}$, T.M. Behr ${ }^{1}$ and H. Höffken ${ }^{1}$ \\ ${ }^{I}$ Department of Nuclear Medicine, Philipps University Marburg, Germany \\ ${ }^{2}$ Department of Nuclear Medicine, University Medical Center Nijmegen, The Netherlands
}

\begin{abstract}
Leukocyte activation is a property of systemic infection. In a previous animal experiment we could demonstrate, that granulocytes, which were already activated by the immune system, were more useful in the evaluation of scintigraphic imaging infection than non activated donor granulocytes. The purpose of the present study was to investigate the in vitro activation of isolated polymorphonuclear (PMN) donor leukocytes in the presence of various biological active modulators in rabbits with $E$. coli infection.
\end{abstract}

Methods: In vitro, incubation of isolated leukocytes of non infected donors was performed with different immune stimulating modulators such as granulocyte-colony stimulating factor (G-CSF), proinflammatory cytokines (IL-8, IL-1 $\beta$ ) and bacterial products (fMLP) at 37 degrees $\mathrm{C}$ for $2 \mathrm{hrs}$. Afterwards, the different radiolabeled granulocyte preparations were studied in rabbits with an E. coli infection in the left calf muscle. The soft tissue infections were scintigraphically visualized following injection of $18 \mathrm{MBq}{ }^{99 \mathrm{~m}} \mathrm{Tc}-\mathrm{HMPAO}$-purified-heterologous in vitro stimulated granulocytes of non infected donor rabbits. Non-stimulated ${ }^{99 \mathrm{~m}} \mathrm{Tc}$-HMPAO-purified-heterologous granulocytes served as a control. Gamma camera images were acquired at $2 \mathrm{~min}, 1,2$ and $4 \mathrm{hrs}$ p.i. After the last image the rabbits were sacrificed and the uptake of the radiolabel in the dissected tissues was determined.

Results: The ${ }^{99 \mathrm{~m}} \mathrm{Tc}-\mathrm{HMPAO}-$ heterologous granulocytes incubated with G-CSF faintly visualized the infectious focus in the calf muscle at $2 \mathrm{hr}$ p.i. and a slightly better delineation of the infection was noticed at $4 \mathrm{hr}$ p.i. With heterologous granulocytes incubated with proinflammatory cytokines and fMLP a delineation of the infected calf muscle was not possible. The absolute uptake in the infected calf muscle was not significantly different between G-CSF $(0.26 \pm 0.06 \%$ ID), proinflammatory cytokines $(0.23 \pm 0.06 \%$ ID), fMLP $(0.22 \pm 0.02 \%$ ID) and the controls $(0.17 \pm 0.02 \%$ ID). The ratio of the infection to the non infected contralateral muscle was slightly higher for ${ }^{99 \mathrm{~m}} \mathrm{Tc}-\mathrm{HMPAO}$-heterologous granulocytes incubated with G-CSF $(2.63 \pm 0.03)$ as compared with the proinflammatory cytokines $(1.3 \pm 0.01)$, fMLP $(1.4 \pm 0.08)$ and the control $(1.4 \pm 0.04$ ), respectively (all statistical differences were not significant with $\mathrm{p}=0.1-0.32$ ).

Conclusions: Our results confirm a direct, but probably weak stimulating effect of only G-CSF on the PMN for imaging infection. In addition, in-vivo heterologous granulocytes harvested from infected animals in a previous study showed better results as compared to the present data, suggesting the need of intrinsic cell activation for specific granulocyte migration, which cannot be mimicked by other stimuli.

Keywords: Radiolabeled leukocytes, ${ }^{99 \mathrm{~m}} \mathrm{Tc}-\mathrm{HMPAO}$, in vitro incubation of granulocytes.

\section{INTRODUCTION}

Polymorhonuclear leukocytes (PMN, neutrophils) play an important role in the primary immunological defense against infectious agents [1]. Typically, PMN have a relatively short biological half-life within they have to be recruited to a site of inflammation. In this regard, the migration capacity of PMN is influenced by different factors such as cytokines (e.g. Interleukin-1 $\beta$ (IL-1 $\beta$ ), Interleukin-8 (IL-8)), granulocyte-colony stimulating factor (G-CSF), bacterial products (e.g. N-formyl-methionyl-leukyl-phenylalanine (fMLP)) and others [2]. Chemotaxis to the site of infection is caused by these inflammatory mediators, since chemotactically activated PMN are drawn along a concentration gradient following occupation of surface receptors of these mediators $[3,4]$.

*Address correspondence to this author at the Department of Nuclear Medicine, Seelbergstraße 11, D-70372 Stuttgart, Germany; Tel: 011 - 49 - 7115538241; Fax: 011 - 49 - 711-5538246;

E-mail: Nuklearmedizin-Gratz@gmx.net
In addition, granulocyte-colony stimulating factors cause the release of PMN from bone marrow reserves and stimulate a further production of PMN [5].

In nuclear medicine, the use of ${ }^{111} \mathrm{In}[6-8] /{ }^{99 \mathrm{~m}} \mathrm{Tc}$ HMPAO [9]-labeled autologous purified granulocytes, which already are chemotactically activated, are the "gold standard" for the scintigraphic localization of abscesses in febrile patients. Radiolabeled autologous granulocytes allow rapid visualization of infected and inflamed foci within $1-4$ hours after intravenous (i.v.) reinjection. Various clinical trials showed, that radiolabeled leukocytes demonstrated accurate evaluation of inflammatory lesions with a sensitivity and specificity of $84-96 \%$ and over $96 \%$ [10] respectively.

Previously we could show in an animal model [1], that chemotactically activated ${ }^{99 \mathrm{~m}} \mathrm{Tc}-\mathrm{HMPAO}$-labeled granulocytes derived from autologous and heterologous infected animals had equally better characteristics for localizing a bacterial infection compared to ${ }^{99 \mathrm{~m}} \mathrm{Tc}-\mathrm{HMPAO}$-heterologous granulocytes of non infected donors. Abscess uptake and 
abscess-to-muscle ratios obtained with ${ }^{99 \mathrm{~m}} \mathrm{Tc}-\mathrm{HMPAO}-$ autologous granulocytes and ${ }^{99 \mathrm{~m}} \mathrm{Tc}-\mathrm{HMPAO}-$ heterologous granulocytes of infected donors exceeded the value of ${ }^{99 \mathrm{~m}} \mathrm{Tc}$ HMPAO-heterologous granulocytes of non infected donors by $67 \%$ and $52 \%$ respectively. These observations suggested, that the in vivo environment of the leukocytes before isolation determined their migratory capacity.

It has been postulated, that the migration of leukocytes to perivascular infected tissue is multifactorial and is not only depending on chemotactic proinflammatory cytokine responses [11] but also on the expression of adhesion molecules [12] and the mobilizing capacity of marginating granulocytes due to different stimuli [10].

For this reason we investigated in the present study, whether the migration capacity of non- activated donor granulocytes from healthy rabbits can be improved by in vitro stimulation with biological cell activation factors of different origins.

\section{MATERIAL AND METHODS}

\section{Animal Model}

Abscesses were induced in the left thigh muscle of twenty five female New Zealand rabbits $(2.4-2.7 \mathrm{~kg})$ with $0.5 \mathrm{ml}$ of $2 \times 10^{11}$ colony forming units (cfu) $/ \mathrm{ml} \mathrm{E}$. coli suspension of Escherichia coli in $0.5 \mathrm{ml}$. During the procedure, rabbits were anaesthetized with a subcutaneous injection of $0.6 \mathrm{ml}$ mixture of fentanyl $0.315 \mathrm{mg} / \mathrm{ml}$ and fluanisone $10 \mathrm{mg} / \mathrm{ml}$ (Hypnorm, Janssens Pharmaceutical, Buckinghamshire, UK). After 24 hours, when swelling of the muscle was apparent, five groups of five animals (group AE) were formed. Experiments were performed in accordance with the guidelines of the local animal welfare committee.

Granulocyte isolation: The isolation of granulocytes was performed according to the method described by Lillevang et al. [13] with minor modifications [14]. Briefly, the blood of 5 donor rabbits $(5 \times 100 \mathrm{ml})$ was mixed with 0.1 volume of $6 \%$ dextran (Dextran $(267 \mathrm{kDa})+\mathrm{ACD}$ solution in $0.9 \%$ $\mathrm{NaCl}$ and allowed to settle for $1 \mathrm{hr}$ at room temperature. The leukocyte-rich supernatant was layered carefully on $1 / 3$ volume of Nycoprep density medium (14.1\% Nycodenz, $0.3 \%$ $\mathrm{NaCl}, 5 \mathrm{~m} M$ Tricine $/ \mathrm{NaOH} \mathrm{pH} 7.2$, density $=1.077 \mathrm{~g} / \mathrm{ml}$, osmolality $=265 \mathrm{mOsm}$ : Nycomed, Oslo, Norway) and centrifuged for $15 \mathrm{~min}$ at $600 \mathrm{~g}$. The plasma above the mononuclear cells, the mononuclear band and the density medium above the granulocyte pellet were carefully removed. The pellet was washed with $5 \mathrm{ml}$ Hank's balanced salt solution (HBSS) with $10 \%$ autologous plasma and centrifuged for 10 min at $50 \mathrm{~g}$. The cell pellet was resuspended in $1.5 \mathrm{ml}$ HBSS, $10 \%$ rabbit plasma. After this purification procedure the granulocyte purity exceeded $95 \%$ for each preparation.

Cell labeling procedure: around $370 \mathrm{MBq}$ freshly prepared ${ }^{99 \mathrm{~m}} \mathrm{Tc}$-HMPAO was added to the $500 \mathrm{ml}$ cell suspension. The cells were incubated with ${ }^{99 \mathrm{~m}} \mathrm{Tc}-\mathrm{HMPAO}$ at room temperature for $30 \mathrm{~min}$ and centrifuged for $10 \mathrm{~min}$ at $50 \mathrm{~g}$. The pellet was resuspended in $25 \mathrm{ml}$ of cell free autologous plasma and than divided into 5 equal portions (A-E). Labeling efficiency (Cell associated activity / total activity added) was $40-50 \%$ for the different granulocytes preparations. Each portion of cell suspension than was incubated with one of the biological active stimulators.
Cell incubation procedure: A) Control: the control granulocytes were left with $5 \mathrm{ml}$ HBSS (Hanks buffered salt solution) containing $0.5 \% \mathrm{BSA}$.

The cell suspensions (B-E) were equally brought to $5 \mathrm{ml}$ and incubated with B) G-CSF: $0.2 \mu \mathrm{g} / \mathrm{ml}=1 \times 10^{-8} \mathrm{M}$, C) IL8: $0.2 \mu \mathrm{g} / \mathrm{ml}=2 \times 10^{-8} \mathrm{M}$, D) fMLP: $0.04 \mu \mathrm{g} / \mathrm{ml}=1 \times 10^{-7} \mathrm{M}$ and E) IL-1 $\beta$ : $2 \mu \mathrm{g} / \mathrm{ml}=1 \times 10^{-7} \mathrm{M}$.

Functional integrity of labeled granulocytes was evaluated by their in vivo performance, including transit through the lungs, hepatic- and splenic uptake. A dose of $18 \mathrm{MBq}$ ${ }^{99 \mathrm{~m}}$ Tc-labeled granulocytes was administered intravenously in each rabbit.

\section{Radiopharmaceuticals}

${ }^{99 m}$ Tc-HMPAO- purified granulocytes derived from 5 non infected donor rabbits: The right carotid artery of each rabbit was canulated and a total amount of $100 \mathrm{ml}$ blood was drawn from each rabbit into an acid citrate dextrose-tube (containing $14 \mathrm{ml}$ 6\% Dextran $(267 \mathrm{kMol})$ (Sigma-Aldrich, Zwijndrecht, NL) $+8 \mathrm{ml}$ acid citrate dextrose (ACD) (NPBIBiotrans $\mathrm{GmbH}$, Dreieich, Germany) per $100 \mathrm{ml}$ blood). The leukocyte count in the full blood of the rabbits ranged from 7.7 to $8.2 \times 10^{9} / \mathrm{L}$ with approximately $70 \%$ granulocytes. After granulocyte isolation, the cell count ranged from 8.2 to $10.0 \times 10^{9} / \mathrm{L}$ (measured in the same volume) with $>95 \%$ granulocytes.

\section{Gamma Camera Imaging and Data Analysis}

For imaging, rabbits were immobilized in a mold and placed prone on the gamma camera. Five rabbits of each group (A-E) were injected either with $18 \mathrm{MBq}{ }^{99 \mathrm{~m}} \mathrm{Tc}$ HMPAO-autologous purified granulocytes (Control, group A) or ${ }^{99 \mathrm{~m}} \mathrm{Tc}-\mathrm{HMPAO}$-biologically activated granulocytes $(\mathrm{G}-$ CSF, group B and IL-8 (group C), fMLP (group D) and IL$1 \beta$ (group E) via the ear vein. Three rabbits of each group were used for gamma camera imaging. Images were recorded at $2 \mathrm{~min}, 1,2$ and $4 \mathrm{hr}$ p.i. with a single-head gamma camera (Orbiter, Siemens Medical Systems Inc., Hoffman Estates, IL) equipped with a parallel-hole low-energy all purpose collimator. Images were obtained with a $15 \%$ symmetrical window over the $140 \mathrm{keV}$ energy peak of ${ }^{99 \mathrm{~m}} \mathrm{Tc}$. After acquisition of 300,000 counts, the images were digitally stored in a $256 \times 256$ matrix.

Scintigraphic images were analyzed quantitatively by drawing regions of interest (ROI) over the abscess and the noninfected contralateral thigh muscle (background). Abscess-to-background ratios, lung-to-liver ratios as well as uptake measurements of various organs (kidney, liver, spleen) were calculated.

After acquiring the final images, rabbits were sacrificed with an overdose of sodium phenobarbital and biodistribution of the radiolabeled tracers was determined. Blood was obtained by cardiac puncture. Tissues [lung, liver, spleen, kidney, small intestine, colon, infectious left calf muscle, non infected contralateral muscle] were dissected, weighed and the radioactivity was measured in a shielded well-type gamma counter (Wizard, Pharmacia-LKB, Sweden). To correct for decay and to permit calculation of the uptake of the radiolabeled leukocyte preparation in each organ as a fraction of the injected dose, aliquots of the injected dose $(1 \%)$ 
were counted simultaneously. The results were expressed as percent injected dose per gram $(\% \mathrm{ID} / \mathrm{g})$ and as percent injected dose (\%ID) (for the abscess).

\section{Statistical Analysis}

All mean uptake values are given as percent of the injected dose per gram $(\% \mathrm{ID} / \mathrm{g})$ and as percent of the injected dose (\%ID) (for the abscess) \pm one standard error of the mean (s.e.m.). The one-way-analysis-of variance (ANOVA) was used to compare the uptake in the infected calf muscle and the non infected contralateral muscle, using the GraphPad InStat 3.00 software package (GraphPad Software, San Diego, CA., USA). The level of significance was set at $\mathrm{p}<$ 0.05 .

\section{RESULTS}

With the inoculum of $0.5 \mathrm{ml}$ of $2 \times 10^{11} \mathrm{cfu} / \mathrm{ml} E$. coli suspension all rabbits $(n=25)$ developed a soft tissue infec- tion in the left thigh muscle within $24 \mathrm{hr}$ after bacterial inoculation. A gross swelling of the left thigh muscle and redness of the skin was apparent in all rabbits. Cross-sections of the abscess sample macroscopically showed the presence of encapsulated purulent material. The scintigraphic images of the respective radiolabeled granulocyte preparations at $4 \mathrm{hr}$ postinjection are shown in Fig. (1).

Quantitative analysis of the scintigrams of ${ }^{99 \mathrm{~m}} \mathrm{Tc}-$ HMPAO-biologically activated granulocytes and ${ }^{99 \mathrm{~m}} \mathrm{Tc}-$ HMPAO-heterologous granulocytes from the control group showed a rapid initial lung transit and low hepatic and splenic uptake, indicating that the ${ }^{99 \mathrm{~m}} \mathrm{Tc}$-labeling procedure did not damage granulocyte function (Fig. 2).

${ }^{99 \mathrm{~m}}$ Tc-HMPAO-heterologous granulocytes incubated with G-CSF faintly visualized the infection at $2 \mathrm{hr}$ p.i. Contrast between abscess and background improved on the subsequent scintigrams with granulocytes incubated with GCSF. The uptake in the abscess of ${ }^{99 \mathrm{~m}} \mathrm{Tc}-\mathrm{HMPAO}$-hetero-

\section{Autologous}

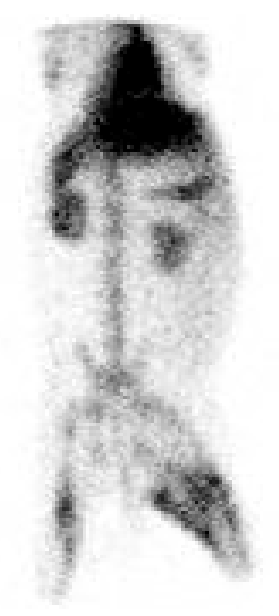

\section{Control}

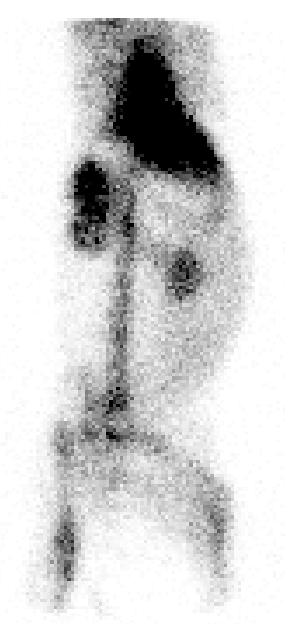

\section{G-CSF}

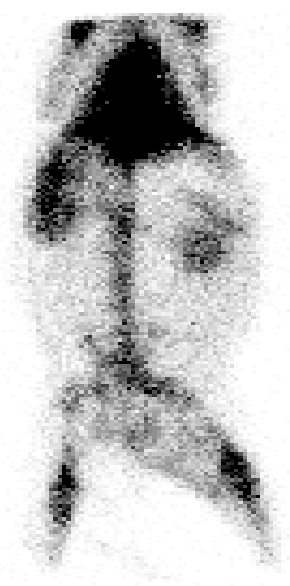

IL-1 $\beta$

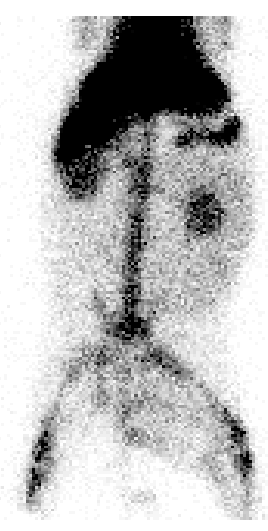

fMLP

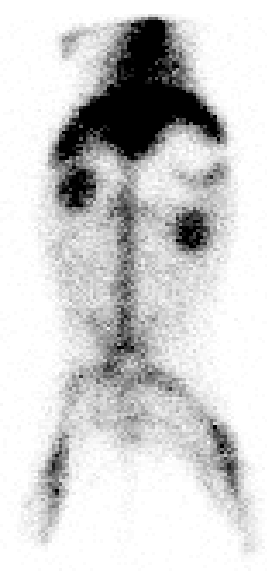

IL-8

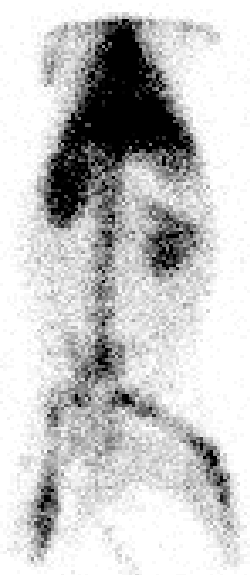

Fig. (1). Scintigrams of rabbits with E. coli infection in the left calf muscle imaged at $4 \mathrm{hr}$ after injection of ${ }^{99 \mathrm{~m}}$ Tc-HMPAO-autologous purified granulocytes incubated with G-CSF, proinflammatory cytokines, fMLP, controls and ${ }^{99 \mathrm{~m}} \mathrm{Tc}-\mathrm{HMPAO}$-autologous stimulated granulocytes. 


\section{Granulocyte kinetics}

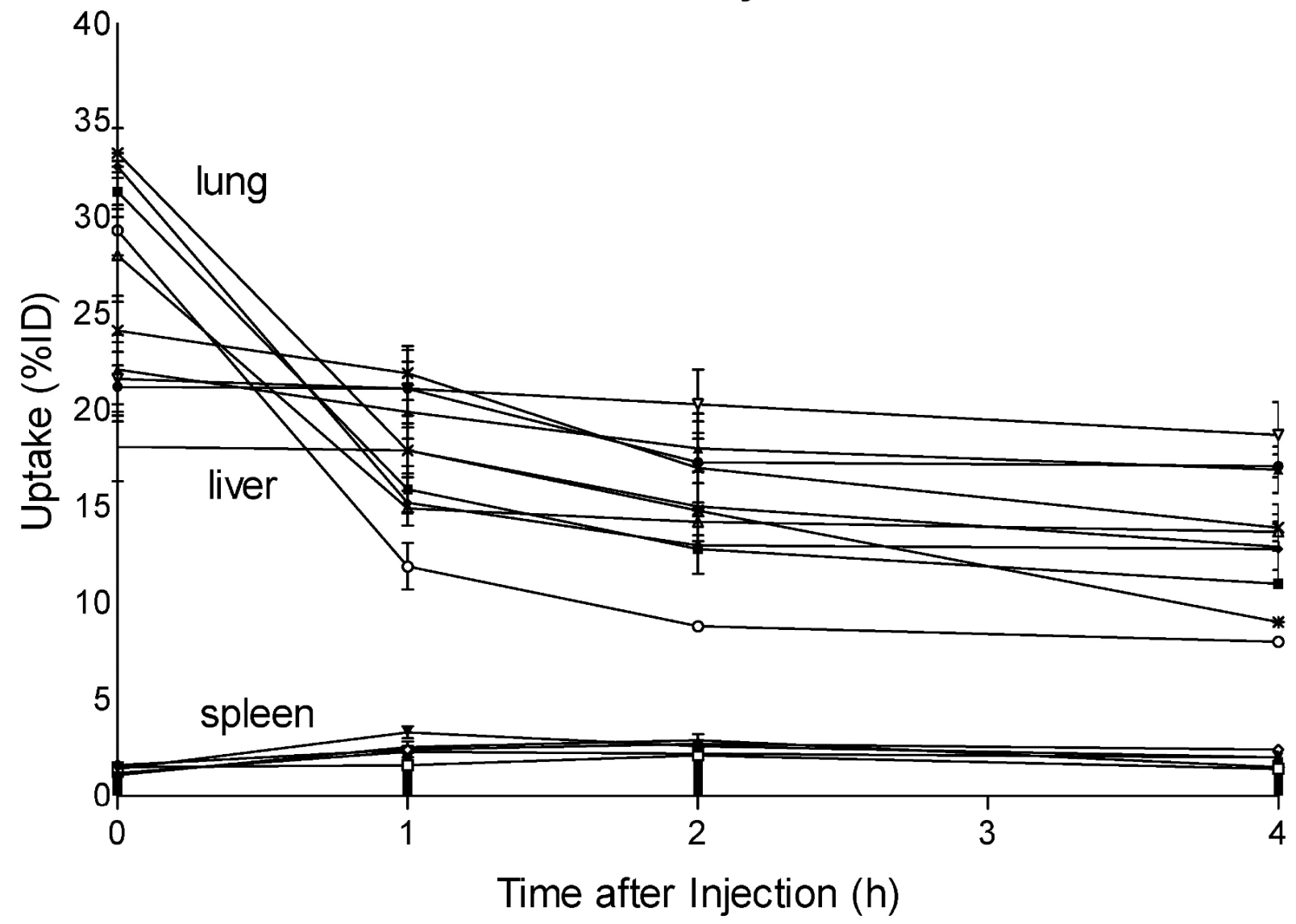

Fig. (2). Quantitative analysis (mean \pm SEM) of the scintigraphic images of rabbits injected with ${ }^{99 \mathrm{~m}} \mathrm{Tc}-\mathrm{HMPAO}$-heterologous granulocytes incubated with G-CSF, proinflammatory cytokines and fMLP. Non stimulated ${ }^{99 \mathrm{~m}} \mathrm{Tc}-\mathrm{HMPAO}$-heterologous granulocytes served as controls, showing clearence from the lungs, the liver and spleen. Whole-body activity measured at 2 min p.i. was set at $100 \%$, error bars represent SEM.

logous granulocytes incubated with G-CSF $(0.023 \pm 0.005 \%$ ID/g at 4 hr p.i.) was double as high as with ${ }^{99 \mathrm{~m}} \mathrm{Tc}-\mathrm{HMPAO}-$ heterologous granulocytes from the control group $(0.014 \pm 0.001 \% \mathrm{ID} / \mathrm{g}$ at $4 \mathrm{hr}$ p.i.). This allowed a scintigraphic delineation of the infected thigh muscle with ${ }^{99 \mathrm{~m}} \mathrm{Tc}-$ HMPAO-heterologous granulocytes incubated with G-CSF. In contrast, ${ }^{99 \mathrm{~m}} \mathrm{Tc}-\mathrm{HMPAO}-$ heterologous granulocytes from the control group and ${ }^{99 \mathrm{~m}} \mathrm{Tc}-\mathrm{HMPAO}$-heterologous granulocytes incubated with the proinflammatory cytokines and fMLP showed a low uptake in the infected muscle at 1-2 hr p.i. and no further increase of uptake was observed on the later scintigrams.

${ }^{99 \mathrm{~m}}$ Tc-HMPAO-heterologous granulocytes incubated with G-CSF showed continuous increase of $\mathrm{T} / \mathrm{B}$ ratio with time and reached their maximum at $4 \mathrm{hr}$ p.i. $(2.63 \pm 0.03)$, whereas ${ }^{99 \mathrm{~m}} \mathrm{Tc}-\mathrm{HMPAO}$-heterologous granulocytes from the control group and granulocytes incubated with the proinflammatory cytokines and AMLP reached their maximum between $1-2 \mathrm{hr}$ p.i. $(1.4 \pm 0.04,1.3 \pm 0.01$ and $1.4 \pm 0.08$ respectively, statistically all differences were not significant $p=0.15-0.32$ ) and then remained stable. Fig. (3) shows the abscess uptake of the various cell preparations at $4 \mathrm{hr}$ after injection.
The biodistribution data of the radiolabeled granulocyte preparations at $4 \mathrm{hr}$ p.i. are given in Table $\mathbf{1}$. In accordance with the scintigraphic results, ${ }^{99 \mathrm{~m}} \mathrm{Tc}-\mathrm{HMPAO}$-heterologous granulocytes incubated with G-CSF showed slightly higher uptake in the infectious focus at $4 \mathrm{hr}$ p.i. than ${ }^{99 \mathrm{~m}} \mathrm{Tc}$ HMPAO-heterologous granulocytes from the control group or ${ }^{99 \mathrm{~m}} \mathrm{Tc}$-HMPAO-heterologous granulocytes incubated with the proinflammatory cytokines and fMLP $(0.014 \pm 0.001 \%$ $\mathrm{ID} / \mathrm{g}, 0.017 \pm 0.001 \% \mathrm{ID} / \mathrm{g}$ and $0.017 \pm 0.001 \% \mathrm{ID} / \mathrm{g}$ at $4 \mathrm{hr}$ p.i. respectively). The uptake of all radiolabels was comparatively low in normal muscle tissue. Consequently, the abscess-to-muscle ratio for ${ }^{99 \mathrm{~m}} \mathrm{Tc}-\mathrm{HMPAO}-$ heterologous granulocytes incubated with G-CSF $(11 \pm 3)$ was higher as compared to ${ }^{99 \mathrm{~m}} \mathrm{Tc}-\mathrm{HMPAO}$-heterologous granulocytes from the control group and ${ }^{99 \mathrm{~m}} \mathrm{Tc}-\mathrm{HMPAO}$-heterologous granulocytes incubated with the proinflammatory cytokines and fMLP (5-6 \pm 2 , respectively). Each of the preparations showed comparably high uptake in the spleen (between 0.58 \pm 0.0 .1 and $1.4 \pm 0.1 \% \mathrm{ID} / \mathrm{g})$. Liver uptake was similar for all preparations (Table 1). The preparations showed comparably low blood levels, resulting in low uptake in background tissues (muscle, small intestine). Localization in most other tissue samples was remarkably similar. Based on ROI, 


\section{Abscess uptake of the preparations at $4 \mathrm{hr}$ after injection}

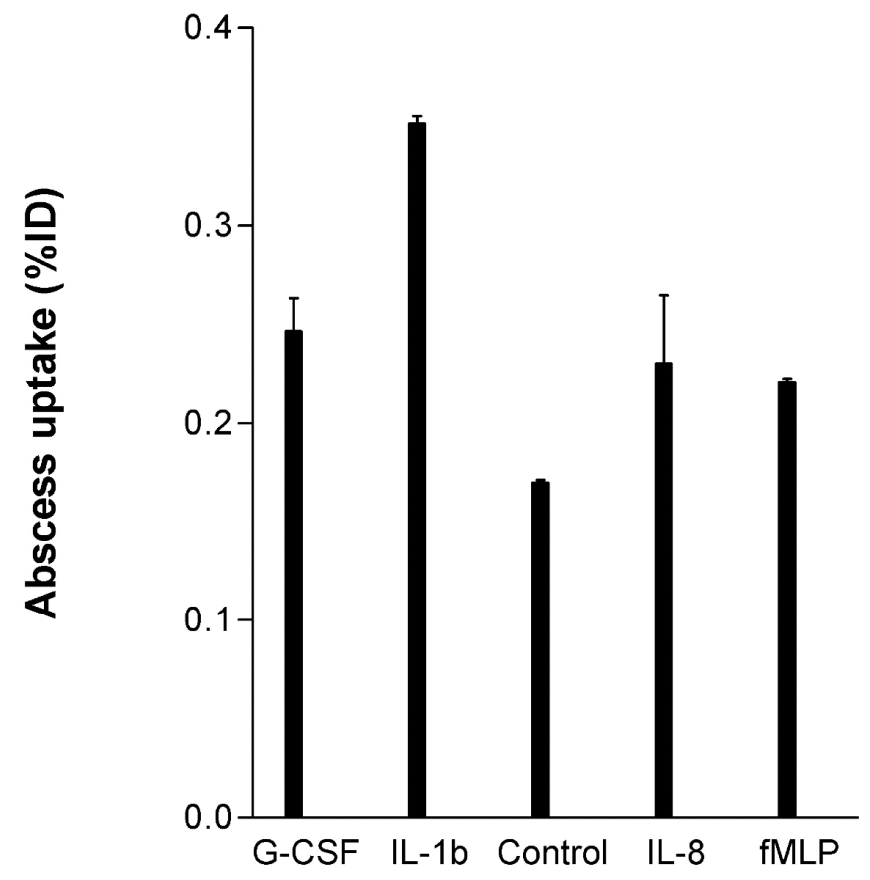

Fig. (3). Abscess uptake (\%ID) of ${ }^{99 \mathrm{~m}} \mathrm{Tc}-\mathrm{HMPAO}$-heterologous granulocytes incubated with G-CSF, proinflammatory cytokines and fMLP. Non stimulated ${ }^{99 \mathrm{~m}}$ Tc-HMPAO-heterologous granulocytes served as controls at $4 \mathrm{hr}$ p.i.

an over time increase in renal ${ }^{99 \mathrm{~m}}$ Tc activity with all labeled granulocyte preparations was noted (from $1.6 \%$ to $2.9 \%$ ID for G-CSF, from $2.2 \%$ to $3.3 \%$ ID for the proinflammatory cytokines and from $1.8 \%$ to $2.9 \%$ for fMLP and heterologous not activated granulocytes, $\mathrm{p}<0.17$ ), reflecting the excretion of ${ }^{99 m}$ Tc-HMPAO complexes eluted from labeled cells. Kidney uptake was similar for the preparations. All values of ${ }^{99 \mathrm{~m}} \mathrm{Tc}-\mathrm{HMPAO}$-granulocytes incubated with IL-8 and IL-1 $\beta$ were in the same range, for this reason the data of IL-1 $\beta$ are not shown.

\section{DISCUSSION}

Expression of the inflamatory process is dependent on mobilization of PMN, which require leukocyte chemotaxis. In vivo, the chemotactic stimuli (factors) for leukocyte activation and migration include a combination of products of different proinflammatory cytokines, such as various interleukines (e.g. IL-1 $\beta$, IL-8 etc.), products of bacterial growth (e.g. fMLP), products of granulocyte mobilization (e.g. GCSF) as well as products of complement activation, collagen products and others. The mechanism by which PMN respond to these chemotactic factors is poorly understood, but cell adherence to the substratum, cell deformability, random migration, and especially directed migration are required [15]. These processes are complex and need modifications of the PMN surface, calcium and magnesium, activation of esterases and function of contractile elements [15].

Already in the early $70 \mathrm{es}$, extensive in vitro studies using the Boyden chamber assays elegantly demonstrated, that a number of exogeneous and endogeneous stimulating factors important in inflammation could show to be capable of activating the various protein systems of PMN responsible for generation of chemotactic response $[16,17]$. In vitro, potentially important interaction between these stimulating factors such as proinflammatory cytokines and granulocyte stimulating factors, and the complement, the fibrinolytic system, the Hageman factor etc. was shown [18]. However, the physiological relevance of this has yet to be established.

Previously, we could demonstrate [1] the remarkably superior quality of already chemotactically activated ${ }^{99 \mathrm{~m}} \mathrm{Tc}$ HMPAO-labeled granulocytes derived from autologous or heterologous infected animals over ${ }^{99 \mathrm{~m}}$ Tc-HMPAO-labeled granulocytes derived from healthy donor rabbits for imaging infection. These observations suggested that the in vivo environment of the leukocytes before isolation determined their migratory capacity.

Table 1. Biodistribution of ${ }^{99 \mathrm{~m}}$ Tc-HMPAO-Heterologous Granulocytes Incubated with G-CSF, IL-8 and fMLP in Rabbits with $E$. coli Abscess 4 hr p.i. Non Stimulated ${ }^{9 \mathrm{~m}}$ Tc-HMPAO-Heterologous Granulocytes were Used as Controls (\%ID/g \pm SEM and \% ID \pm SEM (for the Abscess)). The Level of Significance was Set at $p<0.05$

\begin{tabular}{|c|c|c|c|c|c|}
\hline Organ & Control & p & G-CSF & IL-8 & MLP \\
\hline \hline blood & $0.25 \pm 0.02$ & & $0.29 \pm 0.01$ & $0.25 \pm 0.02$ & $0.26 \pm 0.01$ \\
\hline muscle & $0.002 \pm 0.01$ & & $0.0025 \pm 0.0006$ & $0.018 \pm 0.0002$ & $0.0022 \pm 0.0003$ \\
\hline abscess & $0.01 \pm 0.01$ & & $0.023 \pm 0.005$ & $0.018 \pm 0.003$ & $0.017 \pm 0.02$ \\
\hline lung & $0.10 \pm 0.14$ & & $0.13 \pm 0.003$ & $0.13 \pm 0.03$ & $0.14 \pm 0.01$ \\
\hline speen & $0.58 \pm 0.10$ & & $0.56 \pm 0.04$ & $0.70 \pm 0.15$ & $0.72 \pm 0.08$ \\
\hline kidney & $0.13 \pm 0.03$ & & $0.13 \pm 0.03$ & $0.14 \pm 0.03$ & $0.14 \pm 0.03$ \\
\hline liver & $0.13 \pm 0.01$ & & $0.12 \pm 0.01$ & $0.13 \pm 0.02$ & $0.17 \pm 0.01$ \\
\hline intestine & $0.01 \pm 0.01$ & & $0.015 \pm 0.001$ & $0.015 \pm 0.02$ & $0.015 \pm 0.01$ \\
\hline infect/muscle & $6.5 \pm 1.5$ & $<0.05$ & $11.9 \pm 3.1$ & $10.3 \pm 2.50$ & $8.3 \pm 1.67$ \\
\hline infect/blood & $0.06 \pm 0.01$ & & $0.08 \pm 0.02$ & $0.07 \pm 0.01$ & $0.07 \pm 0.01$ \\
\hline$\%$ ID abscess & $0.17 \pm 0.02$ & & $0.26 \pm 0.06$ & $0.24 \pm 0.07$ & $0.23 \pm 0.03$ \\
\hline
\end{tabular}


As long as nonspecificity of radiolabeled antibodies and antibody fragments [19-21] cannot be improved by more promissing agents, such as radiolabeled peptides [22-24] the "gold standard" for imaging infection will remain the use of radiolabeled leukocytes [6-9]. This is of particular interest especially in human immunodeficiency virus (HIV-1) antibody-positive patients presenting with fever of unknown origin [25] and immunodeficient patients [26-29], where specific imaging infection is mandatory for accurate therapy. In these groups of patients however, the preparation of radiolabeled autologous PMN comprises a small but definite risk of personel contamination by the patients' blood, inadvertent cross-contamination between patients $[30,31]$ as well as too few PMN for sufficient cell labeling [26-29].

For avoiding these problems radiolabeled donor leukocytes [26-29] were used, but the overall results were mediocre compared to normal patients imaged with autologous radiolabeled leukocytes [22]. The studies suggested that the performance of radiolabeled donor leukocytes in immune compromised patients appears to be suboptimal.

In the present study, radiolabeled granulocytes were incubated with biological active modulators (stimulators) for improving the migration capacity of donor granulocytes in an animal model with $E$. coli infection. Two different proinflammatory cytokines (IL-1 $\beta$, IL-8) as well as a granulocyte growth stimulating factor (G-CSF) and bacterial products (fMLP) were used for in vitro incubation, because they seem best to represent the more important single components of the multifactorial immune system. As one could expect, fairly good results were seen in case of granulocyte incubation with G-CSF, but not with the others.

It has been established, that activation of PMN by G-CSF enhances superoxide $\left(\mathrm{O}_{2}{ }^{-}\right)$release [33] and increases the expression of $\beta$-integrin [34] which leads to an increase in serum concentration of soluble selectins [35]. All these modulatory effects of G-CSF on PMN are critical for adhesive interactions of phagocytes with endothelium and their eventual recruitment and accumulation at the site of infection. For this reason, it is not surprising that ${ }^{99 \mathrm{~m}} \mathrm{Tc}-\mathrm{HMPAO}-$ labeled granulocytes after G-CSF incubation demonstrated the abscess formation fairly well at $4 \mathrm{hr}$ after reinjection. This also can be explained by the physiological distribution of granulocytes in the blood. Approximately one-half of the granulocytes in the peripheral blood are freely circulating while the other half form the marginating pool in the circulation [36]. These marginating granulocytes can be mobilized already by subtle stimuli (10) such as G-CSF.

With respect to the scintigraphic results after incubation of granulocytes with proinflammatory cytokines, both proinflammatory cytokines (IL-1 $\beta$, IL-8) did not show sufficient results. However, in previous studies [37], it was shown that in vitro PMN incubation with IL-1 $\beta$ demonstrated a direct stimulatory effect on granulocytes, which was believed to be oxygen-dependent and similar as described with G-CSF. Bergenfeldt et al. [37] could show, that rhIL-1 $\beta$ elicited a chemiluminescence response directly in PMN when incubated, which could be blocked by IL-1 receptor antagonists. This indicates a specific stimulating effect of rhIL-1 $\beta$ on PMN. Although the mechanisms remain basically unclear, IL-1 $\beta$ seems to be a "primer" [37] of PMN, rendering cells more responsive to second stimuli [38]. In fact, it is known, that in vivo high level expression of G-CSF is induced by IL1 in the course of bacterial infection or lipopolysaccharidestimulated immune responses [39]. Nevertheless, the similar properties of PMN stimulation seem not to result in similar scintigraphic findings with ${ }^{99 \mathrm{~m}} \mathrm{Tc}-\mathrm{HMPAO}$-donor granulocytes incubated with either G-CSF or IL-1 $\beta$. Equally to IL$1 \beta$, no improvement of granulocyte migration capacity could be achieved when granulocytes were incubated with IL-8. In vivo, IL-8 is a potent proinflammatory activator of granulocytes responsible for chemotactic migration of granulocytes into the site of inflammation in patients with inflammatory bowel disease (IBD). In patients with IBD, IL-8 will be generated in the interstitial tissue responsible for the attraction of neutrophils from the circulation into the inflammatory site and thus infiltration of neutrophils in the interstitial tissue, contributing to accumulation and activation of neutrophils in the infected mucosa [1]. Furthermore, in vivo there is a direct effect of IL-1 $\beta$ on other cytokines, e.g. by inducing the secretion if IL-6, IL-8 and G-CSF, but not the other way around [40]. This may explain, why the weak stimulation of IL-8 alone does not allow sufficient cell activation for successful imaging infection with IL-8 incubated ${ }^{99 \mathrm{~m}} \mathrm{Tc}-$ HMPAO-heterologous granulocytes.

This study demonstrated, that the migration capacity of donor leukocytes for imaging infection can slightly be improved by incubation with stimulators such as G-CSF. In comparison with our previously presented data [1], the findings of the present study suggest, that chemotactic activation of granulocytes is multifactorial and that the combination of intrinsic and extrinsic factors determines the ability of granulocytes to localize infection and inflammatory foci earlier compared to in vitro biologically active stimulating factors alone.

\section{CONCLUSION}

In a rabbit model with $E$. coli soft tissue infection ${ }^{99 \mathrm{~m}} \mathrm{Tc}$ HMPAO-heterologous granulocytes of healthy donors, in vitro incubated with G-CSF, provided visualization of the abscess formation at $2-4 \mathrm{hr}$. after i.v. injection, and showed slightly higher focal uptake and target-to-nontarget ratios compared to ${ }^{99 \mathrm{~m}} \mathrm{Tc}-\mathrm{HMPAO}-$ heterologous granulocytes of non infected donors. These results indicate that in vitro incubation of heterologous granulocytes with G-CSF functions a weak stimulating factor. In addition, heterologous granulocytes of infected animals in a previous study [1] showed better results as compared to the present data, suggesting the need of intrinsic cell activation for specific granulocyte migration, which cannot sufficiently be mimicked by other stimuli.

\section{ACKNOWLEDGEMENT}

The study was partially supported by the Deutsche Forschungs Gesellschaft (GR 1735/2-1) (DFG).

\section{REFERENCES}

[1] Gratz S, Rennen HJJM, Behr TM, Boerman OC, Oyen WJG, Corstens FHM. ${ }^{99 \mathrm{~m}} \mathrm{Tc}$-HMPAO-labeled autologous versus heterologous leukocytes for imaging infection. J Nucl Med 2002; 43: 91824.

[2] Smith JA. Neutrophils, host defense, and inflammation a doubleedged sword. J Leukoc Biol 1994; 56: 672-86. 
[3] Ofek I, Rest RF, Sharon N. Nonopsonic phagocytosis of microorganisms and eosinophils. ASM News 1992; 58: 429-35.

[4] Snydermann R, Goetzl EJ. Molecular and cellular mechanisms of leukocyte chemotaxis. Science 1981; 213: 830-7.

[5] Thakur ML, Segal AW, Louis L, Welch MJ, Hopkins J, Peters TJ. Indium-111-labeled cellular blood components mechanism of labeling and intracellular location in human neutrophils. J Nucl Med 1977; 18: 1022-6.

[6] Lord BI, Bronchud MH, Owens S, et al. The kinetics of human granulopoiesis following treatment with granulocyte colonystimulating factor in vivo. Proc Natl Acad Sci USA 1989; 86: 9499503.

[7] Thakur ML, Lavender JP, Arnot RN, Silvester DJ, Segal AW. Indium-111-labeled autologous leukocytes in man. J Nucl Med 1977; 18: 1014-21.

[8] Segal AW, Arnot RN, Thakur ML, Lavender JP. Indium-111labelled leucocytes for localisation of abscesses. Lancet 1976; 2 : 1056-8.

[9] Peters AM, Danpure HJ, Osman S, et al. Clinical experience with ${ }^{99 \mathrm{~m}} \mathrm{Tc}$-hexamethylpropylene-amineoxime for labelling leucocytes and imaging inflammation. Lancet 1986; 2 : 946-9.

[10] Coleman RE. Radiolabeled Leukocytes. Nuclear Medicine Annual 1982. Freeman LM, Weissmann HS, Eds. New York ${ }^{\mathcal{O}}$ : Raven Press 1982.

[11] del Pozo MA, Sanchez-Mateos P, Nieto M, Sanchez-Madrid F. Chemokines regulate cellular polarization and adhesion receptor redistribution during lymphocyte interaction with endothelium and extracellular matrix. Involvement of cAMP signaling pathway. J Cell Biol 1995; 131: 495-508

[12] Springer TA. Traffic signals for lymphocyte recirculation and leukocyte emigration the multi step paradigm. Cell 1994; 76: 30114.

[13] Lillevang ST, Toft P, Nilsen B. A method for isolating granulocytes from rabbit blood without causing activation. J Immunol Methods 1994; 169: 137-8.

[14] Böyum A, Lövhaug D, Tresland L, Nordlie EM. Separation of leucocytes improved cell purity by fine adjustments of gradient medium density and osmolality. Scand J Immunol 1991; 34: 697712 .

[15] Gallin JI, Wolff SM. Leucocyte chemotaxis physiological considerations and abnormalities. Clin Haematol 1975; 4: 567-607.

[16] Gallin JI, Kirkpatrick CH. Chemotactic activity in dialyzable transfer factor. Proc Natl Acad Sci USA 1974; 71: 498-502.

[17] Wright DG, Kauffmann JC, Chusid MJ, Herzig, Gallin JI. Functional abnormalities of human neutrophils collected by continuous flow filtration leukopheresis. Blood 1975; 46: 901-11.

[18] Kay AB, Pepper DS, McKenzie R. The identification of fibrinopeptide $\mathrm{B}$ as a chemotactic agent derived from human fibrinogen. $\mathrm{Br} \mathrm{J}$ Haematol 1974; 27: 669-77.

[19] Dams ET, Oyen WJ, Boerman OC, et al. 99mTc-PEG liposomes for the scintigraphic detection of infection and inflammation clinical evaluation. J Nucl Med 2000; 41: 622-30.

[20] Meller J, Ivancevic V, Conrad M, Gratz S, Munz DL, Becker W. Clinical value of immunoscintigraphy in patients with fever of unknown origin. J Nucl Med 1998; 39: 1248-53.

[21] Gratz S, Raddatz D, Hagenah G, Behr T, Behe M, Becker W. 99mTC-labelled antigranulocyte monoclonal antibody FAB' fragments versus echocardiography in the diagnosis of subacute infective endocarditis. Int J Cardiol 2000; 75: 75-84.

[22] Gratz S, Behe M, Boerman OC, et al. (99m)Tc-E-selectin binding peptide for imaging acute osteomyelitis in a novel rat model. Nucl Med Commun 2001; 22: 1003-13.
[23] Gratz S, Rennen HJ, Boerman OC, Oyen WJ, Burma P, Corstens FH. (99m)Tc-interleukin-8 for imaging acute osteomyelitis. J Nucl Med 2001; 42: 1257-64.

[24] Gratz S, Rennen HJ, Boerman OC, Oyen WJ, Corstens FH. Rapid imaging of experimental colitis with $(99 \mathrm{~m}) \mathrm{Tc}$-interleukin-8 in rabbits. J Nucl Med 2001; 42: 917-23.

[25] Prvulovich EM, Miller RF, Costa DC, et al. Immunoscintigraphy with a 99Tcm-labelled anti-granulocyte monoclonal antibody in patients with human immunodeficiency virus infection and AIDS. Nucl Med Commun 1995; 16: 838-45.

[26] Anstall HB, Coleman RE. Donor-leukocyte imaging in granulocytopenic patients with suspected abscesses concise communication. J Nucl Med 1982; 23: 319-21.

[27] Dutcher JP, Schiffer CA, Johnston GS. Rapid migration of 111 indium-labeled granulocytes to sites of infection. N Engl J Med 1981; 304: 3586-9.

[28] Schell-Frederick E, Fruhling J, Van der Auwera P, Van Laethem Y, Klastersky J.111Indium-oxine-labeled leukocytes in the diagnosis of localized infection in patients with neoplastic disease. Cancer 1984; 54: 817-24.

[29] O'Doherty MJ, Revell P, Page CJ, Lee S, Mountford PJ, Nunan TO. Donor leucocyte imaging in patients with AIDS a preliminary report. Eur J Nucl Med 1990; 17: 327-33.

[30] Rojas-Burke J. Health officials reacting to infection mishaps. J Nucl Med 1992; 33: 13N-14N, 27N

[31] Kaim A, Maurer T, Ochsner P, Jundt G, Kirsch E, Mueller-Brand J. Chronic complicated osteomyelitis of the appendicular skeleton diagnosis with technetium-99m labelled monoclonal antigranulocyte antibody-immunoscintigraphy. Eur J Nucl Med 1997; 24: 732-8.

[32] Palestro CJ, Torres MA. Radionuclide imaging of nonosseous infection. Q J Nucl Med 1999; 43: 46-60.

[33] Avalos BR, Gasson JC, Hedvat C, et al. Human granulocyte colony-stimulating factor biologic activities and receptor characterization on hematopoietic cells and small cell lung cancer cell lines. Blood 1990; 75: 851-7.

[34] Zhang P, Bagby GJ, Stoltz DA, Summer WR, Nelson S. Enhancement of peritoneal leukocyte function by granulocyte colonystimulating factor in rats with abdominal sepsis. Crit Care Med 1998; 26: 315-21.

[35] Ohsaka A, Saionji K, Igari J. Granulocyte colony-stimulating factor administration increases serum concentrations of soluble selectins. Br J Haematol 1998; 100: 66-9.

[36] Weiblen BJ, Forstrom L, McCullough J. Studies of the kinetics of indium-111-labeled granulocytes. J Lab Clin Med 1979; 94: 24655.

[37] Bergenfeldt M, Linder C, Ohlsson K. Stimulation of human polymorphonuclear leukocytes by recombinant human interleukin-1 beta. Biol Chem Hoppe Seyler 1992; 373: 255-60.

[38] Sullivan GW, Carper HT, Sullivan JA, Murata T, Mandell GL. Both recombinant interleukin-1 (beta) and purified human monocyte interleukin-1 prime human neutrophils for increased oxidative activity and promote neutrophil spreading. J Leukoc Biol 1989; 45: 389-95.

[39] Shirai R, Kadota J, Tomono K, et al. Protective effect of granulocyte colony-stimulating factor (G-CSF) in a granulocytopenic mouse model of Pseudomonas aeruginosa lung infection through enhanced phagocytosis and killing by alveolar macrophages through priming tumour necrosis factor-alpha (TNF-alpha) production. Clin Exp Immunol 1997; 109: 73-9.

[40] Feghali CA, Wright TM. Cytokines in acute and chronic inflammation. Front Biosci 1997; 2: 12-26. 